\title{
PALABRA MATRIZ Y ESCRITURA POÉTICA: JOSÉ ÁNGEL VALENTE Y LA FABLE MÍSTICA
}

\author{
Pablo Acosta-García \\ Universitat Pompeu Fabra, Barcelona, España \\ pablo.acosta@upf.edu
}

\section{RESUMEN/ ABSTRACT}

En este artículo analizaremos el uso que hace José Ángel Valente del modus dicendi místico para explicar su propia concepción de la poesía. Lo haremos a través de diversos ensayos del autor, que iremos conectando en pos de una sistematicidad de pensamiento. Nos interesa indagar, en primer lugar, en qué concebía Valente como "místico" en relación con su creación lírica. En segundo, nos interesa espigar su poética, ver en qué términos lingüísticos desarrolla la misma y desde qué perspectiva utiliza un lenguaje religioso que, en muchas ocasiones, posee una raíz técnica. Finalmente, abriremos algunos puntos de reflexión sobre el posicionamiento, que vindicamos como absolutamente de consciente, de Valente frente a la tradición mística.

Palabras clave: José Ángel Valente, ensayos, misticismo, poética, apófasis.

\section{WOMB-WORD AND POETIC WRITING: \\ JOSÉ ÁNGEL VALENTE AND THE MYSTIC FABLE ${ }^{1}$}

I will analyze in this article how José Angel Valente uses the mystical modus dicendi to explain his own Poetics. I will do it by studying different essays by the author, looking for

$1 \quad$ Las inquietudes de este artículo surgen de una de las lecciones que impartí, junto a la Dra. Victoria Cirlot (Universitat Pompeu Fabra), en el curso "La identidad de la cultura europea I: La mística en la cultura europea", que se desarrolló en el Col·legi de Doctors i Llicenciats de Catalunya (Barcelona) en el marco de la Universitat Sénior, entre octubre de 2015 y mayo de 2016. Agradezco a sus estudiantes los críticos comentarios que han ayudado en la investigación posterior. Asimismo, querría agradecer a la Dra. Cirlot sus conversaciones sobre Valente y al Dr. Felipe Cussen (Universidad de Santiago de Chile) su lectura atenta y las correcciones hechas a una versión ya avanzada de estas páginas. 
the systematicity of his thought. In the first place, I will focus on what Valente understood by "mysticim" from the point of view of his poetic writing. On the Secondly place, I will study his Poetics in order to analyze the rhetoric of his essays and to analyze his use of a religious technical vocabulary. Finally, I will discuss critically Valente's conscientious use of mystical tradition.

KEYWORDS: José Ángel Valente, essays, mysticism, poetics, apophaticism.

Aprobación: 26/11/2018

\section{INTRODUCCIÓN}

Sin duda, José Ángel Valente es uno de los intelectuales españoles más importantes de la segunda mitad del siglo XX, pero, como creador, también uno de los más disonantes. Frente a la masiva necesidad de componer una poesía crítica o social en los años de la dictadura franquista, Valente crea desde diferentes residencias (Oxford, Ginebra, ya a partir de los ochenta, Almería) una obra que solo parece encontrar parangón en la tradición de la mística hispánica. En este sentido, "palabra matriz" es uno de los sintagmas que él crea para nombrar el objeto de su poesía (Valente, Variaciones 63$)^{2}$. Lo hace en un ensayo contenido en La piedra y el centro ("Sobre la operación de las palabras sustanciales"), donde explica su proceso de escritura como una nueva forma de conocimiento solo aprehensible a través de tal proceso. El fin del mismo es un lenguaje conformado sobre la página, un poema, pero es la vivencia anterior de la escritura la que le permite acceder verdaderamente a una nueva sabiduría. Tenemos aquí in nuce los dos componentes fundamentales de la escritura que modernamente llamamos mística: por un lado, una fable, un modus dicendi, como tan certeramente propuso Michel de Certeau (117), que en el caso valenteano se expresa a través de un lenguaje abigarrado, con claros tintes teológicos y llamadas a diversas tradiciones religiosas; por el otro, una experiencia interior que es un conocimiento nuevo que se dice inefable. En efecto, la escritura mística se construye a través de la tensión indisoluble

\footnotetext{
La primera edición de La piedra y el centro es Madrid, Taurus, 1982. La obra completa de J. Á. Valente ha sido publicada en la siguiente edición: Obras completas. Poesía y prosa, 2 vols., ed. J. S. Robayna, Galaxia Gutenberg, 2010, donde en el segundo volumen se reúnen todos los ensayos que analizaremos en las próximas páginas. A pesar de la existencia de estas obras completas, citaremos cada uno de los libros individualmente, situando los ensayos, así, en su contexto de publicación original.
} 
producida entre lo vivido (que Valente acuñó en otro lugar en su archiconocida fórmula “experiencia abisal") $)^{3}$ frente a su codificación lingüística. Tal y como lo figuró de nuevo Michel de Certeau (117), la escritura mística es la huella de una lucha, la lucha entre el tener que decir y lo que indeciblemente le ha ocurrido al individuo dentro de sít $^{4}$.

La explicación de su creación poética a través de un lenguaje que lo acerca a diversas tradiciones religiosas es un elemento reiterado en la obra de Valente. Especialmente en su obra ensayística toma forma de diversas poéticas que se pueden sistematizar para organizar una concepción coherente de la creación lírica como un acto metódico tendente a lo meditativo 5 . Como sabemos, Valente fue un poeta prolijo, pero también fue profesor, editor, un estudioso de las más diversas temáticas y, en fin, un lector insaciable. De ello da cuenta la citada producción ensayística en la que teoriza no solo sobre sus propios métodos de creación haciendo un amplio acopio de fuentes antiguas y de teóricos del siglo XX, sino también sobre la obra de otros artistas contemporáneos suyos. A pesar de que existen algunos trabajos interesantes que tratan de la relación de Valente con lo sagrado o con su conceptualización del hecho religioso (p. e., Fátima Benlabbah 2008 o Machín Lucas 2010), nos parece enriquecedor abordar aquí un acercamiento crítico a su obra ensayística persiguiendo dos fines: el primero, aclarar cuál es la concepción valenteana de la mística, cómo la utiliza en sus textos y cómo la hace derivar hacia su propia escritura; el segundo, intentar dilucidar cuáles son las relaciones que el mismo autor establece entre experiencia y lengua poética, sobre todo en sus interacciones con las tradiciones místicas que él mismo cita.

\section{LA CONCEPCIÓN DE UNA MÍSTICA SIN TRANSCENDENCIA}

A ningún conocedor de la obra valenteana se le escapa que lo numinoso es una constante temática en su obra. Recorrer sus ensayos, leer su introducción

\footnotetext{
3 "Mandorla: la experiencia abisal". Letras libres.

“Estas 'maneras de hablar' cuentan la lucha de los místicos con la lengua. Más precisamente son las huellas de esa lucha...” (De Certeau 117).

Por supuesto, nos referimos a los pensamientos vertidos por Valente en "Luis Cernuda y la poesía de la meditación". Las palabras de la tribu. La idea del proceso de creación poética como trabajo interior pautado se puede aplicar a la poética del mismo Valente, como explicaremos a lo largo de estas páginas.
} 
sobre su edición de la Guía espiritual de Miguel de Molinos ${ }^{6}$, hojear las actas del congreso que celebraba el cuarto centenario de la muerte de Juan de la Cruz (Valente y Garrido 1995) o internarse en el desnudamiento de su poesía a partir de, al menos, su "segundo modo" (Sánchez Robayna 2014: $47)^{7}$ es toparse una y otra vez con el uso de los lenguajes tradicionales de la religión adaptados a los lenguajes de la creación artística. Por ejemplo, en una reveladora conversación que el poeta sostuvo en 1995, cinco años antes de morir, con el pintor catalán Antoni Tàpies en el estudio del último, leemos lo siguiente:

José Ángel Valente: [...] La modernidad empieza con una hoguera, que es en la que arde el cuerpo de Giordano Bruno, exactamente en el año $1600[\ldots]$. Bruno dijo que la verdadera filosofía es tanto poesía como pintura. La verdadera pintura es tanto música como poesía. La verdadera poesía o música es tanto pintura como cierta divina sabiduría. Esto me parece que plantea de forma muy radical el principio de que toda creación parte de una misma materia.

Antoni Tàpies: Este cuarto elemento, la divina sabiduría, es muy importante. A veces se interpreta mal, porque en una época tan materialista como la nuestra puede parecer un retorno a viejas creencias religiosas institucionales. Pero según cómo lo interpretemos puede ser algo muy actual. (Valente, Elogio 90-91)

En estos dos párrafos podemos percibir una concepción sobre la creación artística ya plenamente madurada por parte de Valente e, incluso, un interés en divulgarla. Sin duda, aquí se enuncia una idea que se encuentra, como veremos, ampliamente desarrollada en otros textos: la religiosidad es un elemento estructural de los seres humanos. Debemos recordar que la generación

6 La primera edición fue publicada como Ensayo sobre Miguel de Molinos. Guía espiritual. Defensa de la contemplación. Barcelona: Barral, 1974; posteriormente fue reimpresa con un nuevo prólogo: Miguel de Molinos. Guía espiritual. Defensa de la contemplación (fragmentos). Madrid: Alianza, 1989. Sobre la Guía en la trayectoria de Valente y Zambrano, ver Tatiana Aguilar-Álvarez Bay. "La nada como ejercicio creador. La Guía espiritual de Molinos en Zambrano y Valente".

7 Es el editor de su Poesía completa el que marca dos "modos" en la evolución valenteana: uno, más cercano a los postulados de la "poesía crítica" y otro, posterior a 1980 y al libro Material memoria, en el que el interés por los lenguajes de la mística es evidente. En todo caso, tal y como dice A. S. Robayna en la página citada arriba, estas fronteras son siempre imperfectas y permeables. 
de Valente y Tàpies queda marcada por la España del nacionalcatolicismo ${ }^{8}$. Es desde este contexto desde donde debemos entender la alusión que hace Tàpies a un supuesto retorno a las "viejas creencias religiosas institucionales" como posibles críticas que se le hacen desde su entorno al utilizar terminología metafísica para referirse a sus procesos creativos. Aquí lo que ambos artistas intentan es descuadrar la ecuación "religión es igual a (nacional) catolicismo". Como aclararán más adelante, ambos creadores desean llevar el hecho religioso a un campo antropológico a través del discurso, para entenderlo una característica intrínseca al homo sapiens que ellos entienden como homo religiosus, tal como haría la Historia de las religiones en el siglo XX o, ya en el nuestro, pensadores como Lluís Duch (Duch 66) ${ }^{9}$.

Así pues, Tàpies y Valente utilizarán teóricamente diferentes lenguajes de diversas manifestaciones religiosas, especialmente cercanas a las revelatorias de la mística, para referirse a su creación artística, pero colocándolos siempre en un marco laico, entendiéndolos como la apropiación de un lenguaje que permita construir un proceso de búsqueda de sentido y de plasmación de este en la materialidad de la obra. En el caso de Tàpies, esta concepción de la creación artística como revelación está expresada por él mismo desde una vivencia biográfica que propicia el cambio: una enfermedad pulmonar que en 1942 lo deja postrado durante un año en diversos sanatorios y que se alarga otro año más de convalecencia. Según sus memorias, es este el momento en el que algo cambia dentro de sí y lo encamina, a su salida del sanatorio,

\footnotetext{
Sería pueril ensayar en nota en qué medida la dictadura influyó en el pensamiento de dos artistas que vivieron casi toda su vida bajo la sombra de esta. Baste subrayar algunos hechos acaso directamente relacionados: la biografía de Valente está marcada por una temprana marcha de España en 1954, cuando se muda a Oxford para comenzar su labor docente. Ya en el periodo ginebrino (1958-1982) emprende acciones políticas contra el régimen franquista y, en una visita a Barcelona en 1966 es detenido por la Brigada Político-Social (ver A. S. Robayna 22-36). En el caso de Tàpies, los recuerdos que narrativiza en su "Memòria personal (fragments)" hacen evidente la influencia del contexto político español sobre su vida y pensamiento. Ver L'experiència de l'art. Por último, sugiero ver, a su vez, el estudio de Jordi Ardanuy, "Los ensayos de Valente: Sociología y mística en la fundación del humanismo".

En efecto, Duch habla de religiones histórica y culturalmente articuladas (esto es, de movimientos religiosos basados en la revelación que han encontrado una cristalización institucional en un momento dado) frente a "lo religioso" como una capacidad / necesidad estructural del ser humano, esto es un modo de reaccionar, de simbolizar y entender el mundo, una querencia de saber y unas posibilidades de acceder a esa "divina sabiduría" a la que se alude en el texto. Sobre la perspectiva antropológica de los ensayos valenteanos, se puede consultar el mismo estudio de Jordi Ardanuy referido más arriba (183).
} 
a la búsqueda incesante. Hablando del papel de la religión institucional, él mismo dice que en ese tiempo:

L'existència dels déus va entrar, doncs, per a mi en el món de les "hipòtesis innecessàries". Però, malgrat les meves primeres reaccions radicals, no crec que es pugui dir que jo sentís un menyspreu total pel 'món religiós' i, com aniré explicant, amb els anys vaig anar veient que fins un cert 'misticisme sense transcendència'-en el sentit d'amor pel misteri, d'afany per descobrir el desconegut-era inevitable en la condició humana i fins necessari en totes les activitats. (Tàpies 49)

En la frase "la religión es inevitable en la condició humana i fins necessari en totes les activitats" expresa la arriba mentada estructuralidad del hecho religioso como componente humano. En este sentido, podríamos alinear la obra de Tàpies con las búsquedas interiores de gran parte de los movimientos artísticos del s. XX: así es, al menos, como él se autonarrativiza para la posteridad en diversos escritos (1996: 136-137). Así, este "cert misticisme sense transcendència" del que habla el pintor catalán aquí funda desde su punto de vista, de manera retrospectiva, un momento en su biografía en el que su creación se inserta en una búsqueda interior. Desde la perspectiva de gran parte del arte del siglo XX, lo que Tàpies apunta aquí es que lo espiritual no tiene por qué estar encorsetado en un dogma, sino que ello es un instrumento absolutamente humano que nos permite un saber-otro. Este impulso está presente a su vez en los escritos de Valente. Si continuamos con la conversación que cortamos arriba, leemos:

J.Á.V.: Te diría que ese elemento [la divina sabiduría], por llamarle algo, sería el elemento sacro, que es absolutamente necesario en la creación de cualquier orden. Vuelvo otra vez a la imagen utilizada antes: el creador se mueve en mundos oscuros por donde va tanteando... A.T.: Como un telón de fondo que no sabes si es sacro o profano, porque en el fondo no importa...

J.Á.V.: ... sí, lo que es sacro es la actitud, porque no estás operando con un procedimiento racional. Estás afrontando una realidad que desconoces con instrumentos que no se fundan en la razón...

A.T.: ... que no se pueden explicar, que son mundos inefables...

J.Á.V.: Creo que lo que los explica es la obra de arte.

A.T.: Intelectualmente es imposible. Puede haber un pensador que señale unas analogías o unos símbolos. Quizá algún teólogo un poco heterodoxo puede acercarse. (Valente, Elogio 90-91) 
El vocabulario aquí es revelador, porque compone un sistema binario de pensamiento: lo que ambos artistas adjudican al campo semántico de la razón (Valente habla de "procedimiento racional" y de razón; Tàpies usa el adverbio intelectualmente) se contrapone radicalmente a una actitud o un procedimiento que califican de sacro. Además, Valente, de una manera que se repite constantemente en sus escritos, vincula este proceso sacro a lo oscuro, una especie de noche en la que se tiene bucear a ciegas para encontrar, en su caso, la palabra verdadera. Así, esta discusión se desarrolla a través de un metalenguaje, de una construcción teórica que utiliza la terminología de la religión y que la trasvasa al mundo de la creación. Por otro lado, ambos artistas expresan un paradójico deseo de "trascendencia intrascendente" en un mundo en el que los esquemas y los conceptos absolutos ya no son válidos, y en el que la idea de un Dios oficial, unánime, está desfasada.

En todo caso, antes de internarnos en las poéticas de Valente, me gustaría hacer una aclaración: tanto él como Tàpies utilizan de manera ecléctica y sincrética una serie de fuentes de origen culto, que aquí no están citando, dada la naturaleza oral de este texto, y que en los ensayos valenteanos muchas veces se nombran y otras no. En el caso de Valente, podemos afirmar sin duda que era un lector de largo recorrido, que conocía y se interesaba tanto por las novedades intelectuales publicadas en su época como por la lectura directa de fuentes. Al ser un académico, en la obra ensayística valenteana el uso de fuentes casi contemporáneas como material intelectual que explicara sus vivencias con la palabra poéticas es señera. Por ejemplo, en un ensayo titulado "Sobre el lenguaje de los místicos: convergencia y transmisión", leemos lo siguiente:

Durante el otoño de 1924, Rudolf Otto dicta en EE.UU. las conferencias que iban a formar la base de un libro desde muchos puntos de vista fundamental, Mística de Oriente y mística de Occidente, donde establece un sorprendente sistema de afinidades entre Sankara (800 d.C.), el maestro hindú de la no-dualidad, y Eckhart, el maestro renano de la unidad simple. Por razones obvias, el examen de una posible cadena de transmisión quedaba absolutamente excluido en este caso. Así pues, el fascinante trabajo de Otto demuestra por sí solo la existencia de estructuras homogéneas en el fenómeno místico, cualesquiera que sean su latitud y tiempo. Ciertas experiencias extremas tienden a formas análogas de lenguaje (o de suspensión del lenguaje) y a formas análogas de simbolización. Esa homogeneidad no excluye la diferenciación. Al contrario "la esencia de la mística 
-escribe Otto-solo se obtiene de la totalidad de sus diferenciaciones posibles". (Valente, Variaciones 166-167) ${ }^{10}$

La visión de Valente sobre la experiencia hierofánica y su simbolización (de nuevo las dos polaridades fundamentales de toda escritura mística) es clara. Lo que se vindica aquí, utilizando el análisis de Otto, es que la fable de Certeau, que ya hemos citado, se alarga hasta Oriente. En el texto, Valente habla de "estructuras" [lingüísticas], y de "formas... de lenguaje... y simbolización": expresa, pues, la idea de que la mística es un modus dicendi universal que, por supuesto, contiene diferencias culturales. Este estudio y utilización de los grandes hermeneutas de la religión del siglo XX es constante en la obra ensayística de Valente, y sus análisis y vocabulario le sirven para explicar los procesos de su propia creación poética dentro de un ámbito numinoso. Así, él ubica su escritura en una fenomenología sagrada. Siguiendo su línea de razonamiento:

Las manifestaciones diferenciales del fenómeno místico están determinadas por los distintos contextos religiosos o culturales, pero también los exceden. De ahí que un dominico alemán del siglo XIII pueda resultar en ciertos aspectos esenciales más próximo de la mística Vedânta o de la mística Mahâyana que de la mística de Plotino, no obstante los obvios condicionamientos de su propia tradición. De ahí también que en la obra de la 'profetisa germánica' H. de Bingen, escrita más de un siglo antes que la de Eckhart, advierta Hans Liebeschütz la presencia de elementos propios de las cosmologías iraníes. O que Swami Siddheswarananda pueda escribir: 'Cuando los numerosos visitantes indianizantes que acuden a nosotros deploran con un sentimiento de inferioridad que no exista en la tradición cristiana ningún equivalente del Raja-yoga, les aconsejamos que lean muchas veces las obras completas de san Juan de la Cruz, como hemos hecho nosotros mismos, y podemos decir sin ninguna duda, que consideramos a san Juan de la Cruz como el Pantajali de Occidente"'. (Valente, Variaciones 166-167)

La característica principal de este texto es su forma de construir la autoridad a través de las referencias ágiles a estudiosos activos en la primera mitad del siglo XX, cuya cita apoya, en fin, la idea de la universalidad del fenómeno 
místico. Aquí, Valente vuelve al tema de la unidad de lenguaje a través, en este caso, de la idea del exceso expresivo, que puede llegar a igualar la obra de autores muy distantes. Las autoridades que utiliza son los estudios comparativos de Hans Liebeschütz, Swami Siddheswarananda y del mismo Otto. En nuestra opinión, bajo las frases de este ensayo subyace el regocijo del encuentro o, al menos, de la sistematización de un corpus que permite a Valente explicarse el itinerario de su "segundo modo" poético. Los estudios citados, puestos el uno al lado del otro, permiten al poeta fundar una base teórica que explica la esencia de su experiencia creativa ${ }^{11}$. En efecto, el encuentro no solo con fuentes afines (Juan de la Cruz, Molinos, Eckhart), sino con la autoridad de estudiosos del siglo XX que le permiten conectar su quehacer poético con diversas tradiciones religiosas, sus doctrinas y su imaginario, es una constante en el pensamiento valenteano.

\section{LA PALABRA MATRIZ Y LA ENCARNACIÓN}

"En el jardín original se consuma la caída, la catástrofe primordial, que destruye la situación paradisiaca en el amanecer del tiempo. La nostalgia del paraíso perdido es el deseo no extinguido de reconstruir el lenguaje primordial". (Valente, Elogio 65)

En Elogio del calígrafo se publica póstumamente un ensayo titulado "La lengua de los pájaros" donde Valente (63-88) coloca el jardín como símbolo en el centro del texto, relacionándolo con su búsqueda poética. Este símbolo tradicional es utilizado por el autor para construir un mito de la edad dorada a través de un lenguaje extremadamente lírico. En el transcurso del texto se refiere a un momento de la historia en la que el hombre hablaba una suerte de lenguaje divino, "el lenguaje de los pájaros", que en su narración significa una palabra pre-babélica, pura, espiritualizada, semejante, sin duda, a ciertos conceptos que el poeta ya había desarrollado en varios de sus ensayos publicados en vida. Por ejemplo, reproduciendo el contexto del término que encabeza este artículo:

11 V. Es imposible aquí realizar un estudio sobre la complementariedad de las concepciones místico-poéticas en los escritos de Zambrano y Valente, aunque lo contactos (históricos, estilísticos e intelectuales) son abundantísimos: baste como ejemplo las páginas del ensayo "El filósofo", en Los bienaventurados. 
Palabra total y palabra inicial: palabra matriz. Toda palabra poética nos remite al origen, al arkhé, al limo o materia original, a lo informe donde se incorporan perpetuamente las formas. Palabra absoluta que, como escribe Scholem desde la tradición hebrea, "está todavía sin significación en ella misma, pero preñada de significación".

Palabra inicial o antepalabra, que no significa aún porque no es de su naturaleza el significar sino el manifestarse. Tal es el lugar de lo poético. Pues la palabra poética es la que desinstrumentaliza al lenguaje para hacerlo lugar de la manifestación.

[...] Palabra ininteligible, que exige al entendimiento abandonar -dice Nicolás de Cusa- "los caracteres propios de las palabras que utilizamos". Palabra, pues, que se niega a una función utilitaria, que niega el lenguaje como pura instrumentalidad, que apunta esencialmente a un saber del no saber, a un entender del no entender y cuyo solo entendimiento es [...] un intelligere incomprehensibiliter: un entender incomprensiblemente. Tal es el lugar de la palabra que Juan de la Cruz describe en las Coplas sobre un éxtasis de harta contemplación: "entréme donde no supe / y quedéme no sabiendo [...] el espíritu dotado / de un entender no entendiendo / toda ciencia trascendiendo". (Valente, Variaciones 63-66) ${ }^{12}$

Reconocemos de inmediato el estilo de citación de Valente, comparable al del fragmento anterior en su uso de fuentes (aquí primarias), pero con una diferencia: el tono es más ensayístico, más encendido, y el estilo menos académico. Como vemos, el autor traza una clara división que opone dos tipos de lenguaje: por un lado, la palabra formada, instrumental, convencional, que es la que utilizamos cada día para comunicarnos entre nosotros y que posee, por tanto, un sentido común. Por otro, la palabra informe, la palabra matriz o antepalabra, que es la que busca el poeta en la materia oscura, que está preñada de una significación anterior a la convención y que fue parte, en suma, del lenguaje de los pájaros. El primer párrafo habla de esta palabra sin forma, enmarcándola en una suerte de cosmogonía que se levanta, transversalmente, sobre la cábala: la idea esencial es que esa forma presocial de la palabra es informe, pero matérica. En el binarismo palabra matriz-informe-preñadade-significado frente a la palabra instrumental-formada-convencional se construye la retórica de estos dos párrafos, que nos llama de forma particular a

12 Para un acertado comentario a este ensayo, ver Fátima Benlabbah. El espacio de la mediación. J. Á. Valente y el discurso místico. 
la filosofía de María Zambrano, con la que el autor estaba en estrecho contacto en los años de redacción de este escrito. Por otro lado, el encuentro con esa palabra se describe como una manifestación, como una vivencia a la que se le dan todos los rasgos de una hierofanía. Como el poeta gallego dirá con otras palabras: "Todo el que se haya acercado, por vía de experiencia, a la palabra poética en su sustancial interioridad sabe que ha tenido que reproducir en él la fulgurante encarnación de la palabra..." (Valente, Variaciones 67).

En el último párrafo, se introduce la vía negativa cristiana a través de las citas de Nicolas de Cusa y Juan de la Cruz. Como sabemos, el encuentro con el segundo fue fundamental en la trayectoria poética de Valente y, posteriormente, su sombra apofática se complementaría con la de otros autores como Miguel de Molinos o del mismo cusano (Sánchez Robayna 38). La razón para abrazar la apófasis como vía poética está estrechamente relacionada con conceptos como palabra matriz o antepalabra, cuyo encuentro no puede ser sino el resultado de un proceso interior de desnudamiento, de vaciamiento o de negación. Como veremos más adelante cuando analicemos la totalidad del proceso de escritura valenteano, poder alcanzar esa palabra prístina que es el objeto del poeta supondrá una manifestación, una experiencia $y$, en fin, la creación de un poema. Y el lugar donde ocurre todo ello es la nada, lo increado, que en otros textos se figurará como una mandorla, lugar de encuentro "... de lo visible y de lo invisible": "Mandorla, lo cóncavo, lo hueco, la matriz, el vacío, la nada" (Valente 2000²: 45). En efecto, cuando Valente habla de llegar a esta palabra matriz expresa la necesidad de un proceso de de-creación de la palabra vulgar que lo acerca a los itinerarios que buscaban la unión con Dios en lo increado a través del redittus en el neoplatonismo medieval. Así, para Valente, lo poético es un lugar donde la palabra se manifiesta, donde el poeta recibe la manifestación del lenguaje primario y, en fin, donde el proceso poético conlleva una sabiduría-experiencia que solo puede ser expresada en términos negativos: “.... a un saber del no saber, a un entender del no entender y cuyo solo entendimiento es [...] un intelligere incomprehensibiliter". Continúa el ensayo en los siguientes términos:

Esa palabra inicial que dice el principio o el origen es, por eso mismo, la sola palabra que hace posible todo engendramiento. "Palabra-dice M. Zambrano-que no es concepto, pues es ella la que hace concebir". Sólo gracias a esa palabra lo concluso o lo ocluído se abre y la forma reingresa perpetuamente en la formación. Los estoicos la llamaron logos seminal: logos espermático, palabra-semen. Es, en rigor, el soplo del Espíritu, el Pneuma, al que los Padres griegos llamaban, según 
recuerda Ives Congar, Esperma de Dios. De ahí que esa palabra, anterior a la significación, esté grávida o preñada o encinta de todas las significaciones posibles. (Valente, Variaciones 66)

Aquí, la cita a la María Zambrano de Claros del bosque es explícita y es que el logos espermático era un tema de trabajo común entre ambos escritores ${ }^{13}$. Obviamente, Valente está montando aquí un armazón imaginario a través de la creación de espacios y la actuación de agentes en ellos a través de la palabra. Este espacio que aquí se abre es un espacio interior, que él ha llamado lo "poético" anteriormente, y que en la tradición mística cristiana será identificado con el centro alma (Aguirre-Martínez). Como el mismo Valente afirma con una frase difícil, es allí donde "... lo concluso o lo ocluido se abre y la forma reingresa perpetuamente en la formación" (subrayado mío). El espacio de lo poético, la nada, es un lugar donde la consecutividad temporal no existe: es un lugar, pues, similar al apex mentis (el lugar central, más puro del alma) que los místicos neoplatónicos imaginaron como el lugar de la unión con la divinidad y que en la mística medieval del Maestro Eckhart, por ejemplo, se figura de diversas formas para explicar dónde y cómo se produce el nacimiento de Dios continuamente en el hombre (Haas 90-94).

La palabra informe no es, pues, concepto (etimológicamente, algo que ya ha sido concebido), sino un lugar en el que el lenguaje se encuentra desnudo, allí donde se encuentran todas las posibilidades futuras del mismo, y un lugar al que el poeta debe llegar a través de un rechazo de su función utilitaria. Es allí donde reside esta palabra a la vez preñada y preñante, a la que Valente le da aquí un origen divino (soplo del Espíritu, pneuma). Ahora, al poeta solo le queda seguir esta línea de relato para encarnar en uno de los mitos fundacionales del cristianismo su concepción del Logos espermático:

Es indudable que en su amenazada naturaleza mistérica, el cristianismo fija ese instante de aparición o manifestación de la palabra espermática en el misterio de la Encarnación. En definitiva, la más radical noticia que el Evangelio nos da es ésta: el Verbo se hizo Carne. Tanto la como un objeto que ella estaba, en ese momento, estudiando: ver la carta de Zambrano a Valente fechada los días 8 y 9 de 1975, a la que adjunta una copia del texto "Signos, gérmenes". Tera Blanco de Saracho. La esclava y el ángel: correspondencia y dedicatorias entre María Zambrano y José Ángel Valente. Sobre la palabra que concibe en María Zambrano ha escrito Clara Janés: María Zambrano. Desde la sombra llameante. 
experiencia poética como la experiencia religiosa (y distingo ambas experiencias de lo que, respectivamente, podríamos llamar orden de lo literario y orden de lo eclesial) no tienen más espacio para producirse que el generado por esa palabra. Son sustanciación o encarnación de ella. (Valente, Variaciones 67)

En este párrafo, como decimos, nos encontramos ante el encauzamiento del discurso poético hacia un mito que incluye la "experiencia" y la "encarnación" en su enunciación final, es decir, uno de los símbolos esenciales del cristianismo. Hemos llegado a ese punto en el que el mismo autor debe separar los dos ámbitos de su discurso: a pesar de que exista una equivalencia en su funcionamiento interior, y de que se puedan adivinar y nombrar otros referentes históricos que parecen coincidir; finamente, la búsqueda escritural y aquella mística pertenecen a dos ámbitos diversos: el poético y el religioso. Sin embargo, no olvidemos que el lenguaje-posible, la palabra espermática, es un elemento estructural del ser humano que supone el humus común de ambas experiencias. Ese espacio puro, pre-babélico, es el que comparten místicos y (algunos) poetas. Como el mismo Valente afirma en una nota de estas páginas:

No postularíamos aquí ningún nuevo saber, sino muy viejas y sustanciadas formas del saber. Los antiguos habían distinguido con toda precisión el logos endiathetos o verbo interno del logos prophoricos o verbo externo. La palabra va siempre con nosotros aunque callemos o sobre todo cuando callamos. Porque la palabra no destinada al consumo instrumental es la que nos constituye. La palabra que no hablamos, la que habla en nosotros y nosotros, a veces, trasladamos en el decir. Esa palabra interior, que en lo interior se forma y en lo interior de tal modo se sustancia, es asimismo la palabra-materia del poeta, es decir, del hombre cuya experiencia se produce en el extremo límite del lenguaje [...]". (Valente, Variaciones 62, n. 3)

Volvemos a la distinción palabra desinstrumentalizada (logos endiathetos, palabra matriz, interna) frente a la palabra instrumental (logos prophoricos, externa). Así, la experiencia poética que describe Valente no es una experiencia formal, en el sentido de que no trabaja con un lenguaje cotidiano, pre-dado, que obra desde la convención hacia lo externo; ni mucho menos está relacionada con el mundo exterior como la poesía social por la que abogaban otros escritores de su época (Ardanuy 186). Al contrario, estamos, si seguimos a Valente, en una búsqueda matérica, donde materia es igual a palabra-sin- 
forma, es decir una suerte de palabra puramente intelectual y que guarda todas las significaciones posibles en sí misma. Así, en el caso del poeta de Ourense, estamos hablando de una vivencia extrema de lenguaje que "es la que nos constituye": es decir, tal y como indicaban él y Tàpies, que constituía nuestra posibilidad religiosa, lo sacro, en la conversación que comentamos al principio de este artículo.

Lo último que nos resta analizar de la poética valenteana es cuál es el resultado de ese acercamiento a la fuente primera del lenguaje. En los itinerarios místicos a los que Valente hace alusión de manera más común (Juan de la Cruz, Miguel de Molinos, Eckhart...) el fin de cualquier vía mística no es otra que la unión con la divinidad, en diversos grados. Siguiendo la tónica de los fragmentos que hemos analizado, podemos decir que, desde un punto de vista estrictamente poético, lo que se consigue al acercarse a la palabra matriz no es otra cosa que una experiencia de sabiduría.

\section{LA POESÍA-CONOCIMIENTO}

En el momento de la creación poética, lo único dado es la experiencia en su particular unicidad (objeto específico del poeta). El poeta no opera sobre un conocimiento previo del material de la experiencia, sino que ese conocimiento se produce en el mismo proceso creador y es, a mi modo de ver, el elemento en que consiste primariamente lo que llamamos creación poética. El instrumento a través del cual el conocimiento de un determinado material de experiencia se produce en el proceso de la creación es el poema mismo. Quiero decir que el poeta conoce la zona de realidad sobre la que el poema se erige al darle forma poética: el acto de su expresión es el acto de su conocimiento. Solo en ese sentido me parece adquirir su auténtica dimensión de profundidad la afirmación de Goethe: "La suprema, la única operación del arte consiste en dar forma". (Valente, Las palabras 21-22)

Aquí, de manera bastante intrincada, Valente nos describe al menos tres fenómenos que él entiende que constituyen su proceso de escritura, pero que, en el fondo, no están descritos como "partes", sino desde su atemporalidad y su unicidad en tal proceso. Ya remarcábamos arriba que el poeta entiende el lugar en el que lo poético acontece de una manera que se puede poner al lado de las percepciones neoplatónicas que describen el apex mentis, el centro del alma, como el lugar de la manifestación. En este sentido, tanto el lugar de lo poético, como aquel de la unión, no poseen temporalidad. En este 
fragmento, la simultaneidad en el acaecer poético juega con varios elementos que se resisten a ser entendidos de manera consecutiva. Aun respetando este modo de expresión, por mor de claridad, explicamos por separado algunos de los elementos implicados:

El primero, el proceso de creación poética entendido como un itinerario interior que conduce a una experiencia. Este proceso está descrito como un método instrumental (esto es, contiene una finalidad clara y, seguramente, unas fases de acercamiento a la finalidad experiencial) que se renueva en cada búsqueda y cuyo fin es la adopción de un conocimiento-otro que solo se revela al practicarlo y que supone una experiencia. El segundo, esta misma experiencia poética, que engloba al resto de elementos y que se identifica con el "objeto del poeta", es decir tanto con aquello que hace que comience el proceso, como con su objetivo plenamente conseguido. En tercero, tenemos la conformación de la palabra a través de la misma "materia informe" que hemos ido comentando en otros ensayos valenteanos y que él mismo identifica en la conversación con Tàpies como "la materia sobre la que todos los artistas trabajamos".

Así, la búsqueda de la palabra matriz debe ir ligada a la práctica experiencial a través de la cual el poeta rescata las palabras iniciales y les da una nueva forma. El poema, como proceso creador es, a su vez, creador de experiencia $\mathrm{y}$, por tanto, de un conocimiento no aprehensible por otros medios. Llegar a tal vivencia requiere de esta experiencia-conocimiento que es, precisamente, el proceso de creación del poema. El producto final es el mismo texto lírico: una suerte de imagen que ha permitido al poeta dar forma a lo incomprensible, conocer al hacerlo, y que quizá le permita a otros, a sus lectores o auditores, retomar esa experiencia ya formada. Valente nos plantea aquí una imagen cíclica que se retroalimenta, que se encuentra cerca de aquella del ouroboros en su significación autofecundadora (Cirlot, s. v. "ouroboros"). Es lo que repite, enfocando su relato hacia el ámbito externo de la creación, en el siguiente párrafo:

Por eso todo momento creador es en principio un sondeo en lo oscuro. El material sobre el que el poeta se dispone a trabajar no está clarificado por el conocimiento previo que el poeta tenga de él, sino que espera precisamente esa clarificación. El único medio que el poeta tiene para sondear ese material informe es el lenguaje: una palabra, una frase, quizá un verso entero (ese verso que según se ha dicho nos regalan los dioses y que, a veces, debemos devolverles 
intacto). Ese es el precario comienzo. Nunca es otro. (Valente, Las palabras 22)

Así, toda experiencia poética consiste en dar forma, a través del lenguaje, a la materia informe, que en el párrafo superior, él denomina lo oscuro. En este proceso, el resultado formal no es otro que el poema, cuya vehiculación ha constituido la posibilidad al poeta de conocer poéticamente. Ahora bien, desde el punto de vista de la recepción, ¿dónde queda esa experienciaconocimiento? ¿Es posible acceder a ella a través del poema? Valente es preclaro en sus ideas al respecto:

De ahí que se pudiese formular con respecto a la poesía lo que cabría llamar ley de necesidad: hay una cara de la experiencia, como elemento dado, que no puede ser conocida más que poéticamente. Este conocimiento se produce a través del poema (o de las estructuras equivalentes en otros aspectos de la creación artística) y reside en él. Por eso el tiro del crítico yerra cuando en vez de dirigirse al poema se dirige a la supuesta experiencia que lo ha motivado, buscando en ésta la explicación de aquél, porque tal experiencia, en cuanto susceptible de ser conocida, no existe más que en el poema y no fuera de él. (Valente, Las palabras 24)

Como uno de los mayores estudiosos de la mística occidental, Bernard McGinn, advierte en las primeras páginas de su History of Christian Western Mysticism (I, XV), el estudioso que se acerca a "la mística" no debe preguntarse por la veracidad o falsedad de la experiencia que el autor dice haber vivido, sino por la formalización histórica que se realiza de esa misma experiencia y por los sentidos que genera diacrónicamente ${ }^{14}$. Es decir, un acercamiento a un autor místico debe estar basado en una interpretación contextual del texto (entendiendo "texto" en un sentido amplio) y no en disquisiciones externas sobre si el fenómeno sobre el que la fable se construye es creíble o no desde un punto de vista contemporáneo. La razón principal para ello es de índole hermenéutica: el documento es aprehensible, contextualizable e interpretable, pero el fenómeno se nos escapa necesariamente. Precisamente este es el

14 "Theologically speaking, the issue is not, Was this person really a mystic because he or she claims to have had the kind of experience I define as mystical? But, What is the significance of her or his writtings, autobiographically mystical or not, in the history of Christian mysticism?". 
sentido que se expresa en la segunda parte del fragmento citado ("Por eso el tiro..."). Por otro lado, Valente añade a esta una idea sobre la que debemos reflexionar: el conocimiento reside en el poema. ¿Puede, por tanto, un receptor acceder a él desde la lectura del mismo? Es aquí donde nuestro autor acude a Juan de la Cruz para aclarar el sentido de sus palabras:

Hemos escogido el caso del poeta místico por creer que en la experiencia del místico se da de modo especialmente claro para cualquiera aquella condición de toda experiencia que hace que ésta, en su plenitud, desborde la conciencia de un posible protagonista envuelto en ella. Sobre el material dado de su experiencia mística (vivida, pero esencialmente desconocida y oscura), San Juan de la Cruz, por ejemplo, levanta el maravilloso edificio de su Cántico o de su Noche oscura, a través del cual (sólo a través del cual) se produce su propio conocimiento de aquella experiencia en su incambiable particularidad. Por eso, a la hora de escribir sus comentarios, el santo carmelita no trata de explicarnos primero sus experiencias para que entendamos mejor sus poemas, sino que comenta lo que acerca de aquéllas dicen éstos últimos. No podía ser de otro modo, porque aquella experiencia, en cuanto susceptible de ser conocida en su particular unicidad, no existe más que en los poemas del santo. (Valente, Las palabras 24-25)

Valente ejemplifica aquí a través de los poemas y los comentarios de Juan de la Cruz el acercamiento que debe hacerse a una poesía de la experiencia como la suya propia, separando al místico que vive una experiencia extrema y la escribe del místico-como-poeta y, en fin, a este del hermeneuta. Si Juan de la Cruz es llamado místico, nos dice Valente, es porque su experiencia directa de la divinidad se conforma a través de la escritura de sus poemas: no hay experiencia previa (como la hay, por ejemplo, en el caso de Hildegard von Bingen), sino que esta se hace en el proceso de escritura. Por otra parte, como el mismo carmelita demuestra, esta experiencia solo puede ser explicada desde el mismo poema, porque se identifica con su proceso de creación. Esta visión, basada en la lírica como núcleo duro de la mística, es complementaria a la idea de mistagogo que explica Alois M. Haas (67-68) respecto de las enseñanzas de Meister Eckhart ${ }^{15}$. Dentro de la mistagogia,

15 " "...] la mística cristiana no se expresa solamente en géneros literarios adecuados para la transmisión inmediata de la experiencia (relato, carta, poema, etc.), sino, acentuando 
la experiencia personal (esto es, el contacto del alma con Dios) no se hace explícita, sino que se presupone para enseñar un camino a los otros a través del cual podemos llegar a vivir algo similar. En este sentido, los comentarios a sus canciones de Juan de la Cruz son una forma de transmisión para otros de la forma única de su experiencia, que son sus poemas:

De ahí que pudiéramos dar un paso más para decir que a través de los poemas de san Juan de la Cruz un hipotético lector perfecto de su obra podría llegar a conocer la experiencia sobre la que se originaron en el mismo grado en que el poeta la conoció. Digo conocerla, no experimentarla ni vivirla, cosa muy diferente, tan diferente como la vida y la poesía mismas son entre sí. (Valente, Las palabras 24-25)

Aquí se opone de una manera clásica la transmisión de la experiencia a otros, esto es el modus dicendi místico, frente a la experiencia en sí: una cosa son los lenguajes humanos, el cómo codificamos lo vivido; otra es esa vivencia, que es tan intransferible como inenarrable. Así, el conocimiento poético por parte del receptor, tal y como lo muestra Valente, no es racional, sino que el poema construye un puente entre la experiencia del poeta y el conocimiento de la experiencia del lector, a través de la palabra pura recuperada.

\section{CONCLUSIONES}

En este artículo hemos realizado un recorrido intertextual por diversos ensayos en los que José Ángel Valente hace explícita su poética. La expresión con la que lo realiza no es, como hemos visto en estas páginas, casual. Existen una serie de encuentros lectores en su vida (entre los que siempre se ha subrayado el de Juan de la Cruz) que le permiten entender su propia forma

un aspecto teórico de la experiencia, también en géneros cuya tendencia es la introducción a la experiencia mística (mistagogia, mistología): una teoría mística que apunta a su puesta en práctica. / Mientras que el primer tipo de mística literaria (y solo de ella podemos hablar en este lugar) se orienta a la fijación de determinadas experiencias de tipo particular y otorgadas por la gracia como condición para una auténtica experiencia mística, haciendo valer una estructura especial de experiencia religiosa, el segundo tipo está interesado en los momentos objetivamente diagnosticables de la doctrina sobre la experiencia, tiende mucho más fuertemente a la captación intensiva de los contenidos de la doctrina a la luz de un enfoque que ilumina estos contenidos pero que nunca niega su procedencia de la experiencia personal". 
de hacer poesía. Sobre todo durante su "segundo modo", Valente escribe unos ensayos que tienden a la prosa poética y que utilizan un lenguaje fácilmente adscribible a diversas tradiciones religiosas: en este sentido, se alinearía con la práctica de cualquier tradición mística, que es la de aprehender un modus dicendi que, de alguna manera, pueda dar cuenta de una vivencia interior, extrema e inefable. Así, las lecturas que realiza Valente parecen proporcionarle herramientas para un autoconocimiento creativo. Sin embargo, por otro lado, debemos preguntarnos qué significa la tradición para un autor de siglo XX inmerso en una búsqueda ya no de una experiencia mística sin trascendencia (porque en Valente la trascendencia se da), sino de una mística, además, laica y ecléctica.

Como hemos mostrado, Valente era un estudioso de la mística: no solo de las fuentes primarias, sino también de la literatura secundaria que se había generado en el siglo XX sobre el tema. En este sentido, existe cierto academicismo en muchos de sus ensayos, que proviene del uso de ideas que se toman de diversas disciplinas de la investigación universitaria. De esta manera, la ciencia (o, al menos, las ciencias humanas) se constituye como apoyo de una práctica poética que se da antes, durante y posteriormente a esas lecturas. Esta retroalimentación entre conocimiento libresco (reflejado en los ensayos) y conocimiento-experiencia poético parece una constante que acompaña al poeta durante toda su vida. Por otro lado, esta utilización intelectual de las fuentes parece chocar con el uso que hace el poeta de ciertos términos técnicos utilizados en ciertos contextos religiosos (logos endiathetos, logos prophoricos, logos espermático...) que él extrae de sistemas intelectuales muy determinados y reutiliza para hablar de su poética. Sabemos que el ensayo es un ámbito que no exige la referenciación ni la meticulosidad filológica, pero en ocasiones existen términos que se extraen de un contexto muy marcado y que necesitan de un acercamiento precavido. Por ejemplo, cuando habla de las "palabras sustanciales" en la Subida al Monte Carmelo de Juan de la Cruz, nos dice lo siguiente:

Por eso, el místico, es decir el hombre cuya experiencia se produce en el extremo límite de lo religioso, ha tenido siempre una noción propia del funcionamiento de esa palabra, en la que [...] lenguaje y verbo nunca podrán confundirse. Quizá la más bella y sutil consideración que a ese propósito pudiéramos encontrar en la tradición de Occidente esté en los capítulos 29 a 32 de[1 segundo Libro de] la Subida del Monte Carmelo, donde Juan de la Cruz tan precisamente distingue de todas las demás un género de palabras interiores que llama sustanciales, "las 
cuales aunque también son formales por cuanto muy formalmente se imprimen en el alma, difieren, empero, en que la palabra sustancial hace efecto vivo y sustancial en el alma, y la solamente formal no así". (Valente, Variaciones 67-68)

En los capítulos citados, Juan de la Cruz (387-403) escribe sobre las "locuciones", esto es, sobre los discursos que se revelan en el interior del espíritu recogido $\mathrm{y}$ que pueden tener tres diferentes grados: palabras sucesivas, formales y sustanciales ${ }^{16}$. Esta clasificación parte de un uso técnico que el autor está desgranando para un ideal lector espiritual del siglo XVI y que, finalmente, compone un sistema y establece sentidos dentro de tal sistema, así como en un contexto de producción de literatura espiritual muy determinado. En sus ensayos, de una manera indudablemente aguda, Valente elige uno de esos términos clasificados por el carmelita y lo aplica a su propia concepción de una poesía meditativa, a la que él identifica con el recogimiento del que habla el autor. Sin embargo la "palabra sustancial" de Juan de la Cruz es un concepto que se torna lábil sin el sistema psicológico de comprensión del mundo implícito en el discurso del santo que contenía, para empezar, la posibilidad de una revelación lingüística por parte de Dios: ¿dónde está este agente en la poética de Valente, en la que el encuentro con la palabra matriz es causado por la búsqueda activa del poeta? Así, podemos afirmar que la reutilización de lenguaje que realiza Valente siempre es absolutamente consciente, está condicionada por sus necesidades expresivas, y suele apuntar en la dirección de la realización de un encuentro con lo numinoso en el que la gracia está paradójicamente ausente.

Por otro lado, como hemos mostrado en la segunda parte de este artículo, la poética de Valente es completamente coherente a nivel sistemáticoconceptual: se toma un esquema místico neoplatónico que propone de una forma subterránea la idea de redittus y que incluye, finamente, la apófasis como elemento clave en el proceso. El punto de unión entre el itinerario religioso y aquel poético es el lenguaje. Lo que en la mística era una experiencia con lo divino (específicamente en la cristiana podía ser una experiencia del Verbo), en Valente es una experiencia puramente lingüística, pero que tiene consecuencias más allá de una concepción banal de la poesía. El encuentro con la palabra matriz es, para el poeta, una auténtica revelación y, como toda 
hierofanía, supone la adquisición de una nueva sabiduría, de un conocimiento revelado que en contextos tradicionales pudo considerarse santo o herético. El lugar en el que todo ello se produce es la interioridad más íntima, que la tradición cristiana llamaría centro del alma y que Valente llamará mandorla o, simplemente, nada. Los paralelismos entre la experiencia abisal que propone el poeta y aquellas que poseen los místicos son así abundantes y certeras. Como ya hemos dicho, parece existir entre el conocimiento adquirido a través del estudio y aquel vivido en la creación poética una retroalimentación constante: la fable, pues, coincide; aunque las personas del encuentro divergen extrañamente. Como el mismo Valente afirmó en la conversación que citamos en las primeras páginas de este artículo (2002: 95): "El místico quiere llenar el vacío de Dios, tú lo quieres llenar de realidad, una realidad superior a la inmediatamente perceptible".

\section{BIBLIOGRAFÍA}

Aguilar-Álvarez Bay, Tatiana. "La nada como ejercicio creador. La Guía espiritual de Molinos en Zambrano y Valente". Acta Poetica 35/2 (2014): 15-34.

Aguirre-Martínez, Guillermo. "El vacío como fenómeno estético-religioso en la obra de José Ángel Valente". Revista Chilena de Literatura 90 (2015): 7-28.

Ardanuy, Jordi. "Los ensayos de Valente: Sociología y mística en la fundación del humanismo". Pájaros raíces. En torno a José Ángel Valente. Eds. Marta Agudo y Jordi Doce. Madrid: Abada Editores, 2010. 183-201.

Benlabbah, Fátima. El espacio de la mediación. J. Á. Valente y el discurso místico. Santiago de Compostela: Universidade de Santiago de Compostela, 2008.

Blanco de Saracho, Tera. La esclava y el ángel: correspondencia y dedicatorias entre María Zambrano y José Ángel Valente. Moenia 16 (2010): 85-89.

Cirlot, Juan Eduardo. Diccionario de símbolos. Madrid: Siruela, 2001.

De Certeau, Michel. La fábula mística. Trad. de Laia Colell. Madrid: Siruela, 2006.

De la Cruz, Juan. Obras Completas. Ed. Eulogio Pacho. Burgos: Ed. Monte Carmelo, 2000.

Duch, Lluís. La religión en el siglo XXI. Madrid: Siruela, 2012.

Haas, Alois M. M. Eckhart: Figura normativa para la vida espiritual. Barcelona: Herder, 2002. Janés, Clara. María Zambrano. Desde la sombra llameante. Madrid: Siruela, 2010.

Machín Lucas, Jorge. José Ángel Valente y la intertextualidad mística postmoderna: del presente agónico al presente eterno. Santiago de Compostela: Universidade de Santiago de Compostela, 2010.

McGinn, Bernard. The Presence of God. A History of Western Christian Mysticism, 1200-1350, Vol. 1: The Foundations of Mysticism. New York: Crossroad, 1998. 
Sánchez Robayna, Andrés. "Introducción”. Poesía completa. Ed. A. S. Robayna. Madrid: Galaxia Gútenberg, 2014. 9-61.

Tàpies, Antoni. L'experiència de l'art. Ed. J. F. Yvars. Barcelona: Edicions 62, 1996. 25-58. Valente, José Ángel (ed.). Ensayo sobre Miguel de Molinos. Guía espiritual. Defensa de la contemplación. Barcelona: Barral, 1974.

Miguel de Molinos. Guía espiritual. Defensa de la contemplación (fragmentos). Madrid: Alianza, 1989.

Valente, José Ángel. Las palabras de la tribu. Barcelona: Tusquets, 1994.

Variaciones sobre el pájaro y la red precedidos de La piedra y el centro. Barcelona: Tusquets, 2000.

"Mandorla: la experiencia abisal". Letras libres, Año 2/21 (2000): 44-48.

Elogio del calígrafo. Ensayos sobre arte. Barcelona: Galaxia Gútenberg, 2002. 2010. Obras completas. Poesía y prosa. Ed. J. S. Robayna. Barcelona: Galaxia Gútenberg,

Valente, José Ángel y José Luis L. Garrido (eds.). Hermenéutica y mística: San Juan de la Cruz. Madrid, Tecnos, 1995.

Zambrano, María. Los bienaventurados. Madrid: Siruela, 2004. 